\title{
Biodegradation stability of organic solid waste characterized by physico-chemical parameters
}

\author{
N. Cobo, A. López \& A. Lobo \\ Environmental Engineering Group, University of Cantabria, Spain
}

\begin{abstract}
A generalized methodology to characterize the bio-chemical properties of waste results is of great interest in waste management. The chemical and physical methods traditionally used to determine the organic content of solids, such as volatile solids content (VS), total organic carbon content (TOC), cellulose (CEL), hemicellulose (HEM), lignin (LIG), and leaching tests with later analyses of the eluate are easy to perform and to reproduce, but they do not give enough information about the rate of waste stabilization. On account of this, more specific assays like Biochemical Methane Potential (BMP) or respirometry assays are nowadays being performed. These biodegradation assays are more complex because they require extensive time and specific equipments and a number of influencing parameters have to be considered. These difficulties promoted the interest in looking for correlations between "conventional", simpler analyses and biodegradation assays. Based on characterization results obtained by different authors in old waste, ratios between BMP and several parameters are studied in this paper, showing significant correlations in most cases. As a theoretical analysis indicates, only for CEL and CEL+HEM laws that can be generalized to other cases were obtained. VS and (CEL+HEM)/LIG are indicators of the degradation state too, but only with regard to samples of the same type of waste. Since VS content does not inform about organic matter biodegradability and (CEL+HEM)/LIG is independent of the inorganic fraction of waste, the laws BMP/VS and BMP/[(CEL+HEM)/LIG] obtained are different for each studied data series.
\end{abstract}

Keywords: waste characterization, waste stability, analyses correlation, biochemical methane potential (BMP), leaching tests, biodegradation. 


\section{Introduction}

There are a great number of old landfills from which the kind and age of disposed waste as well as their contaminant potential are not well known. This information is necessary as a starting point for the planning and assessment of remediation alternatives (simply lining, in situ bioremediation, landfill mining, etc). With this objective, sampling campaigns and characterization studies are performed.

Generally accepted analyses exist to characterize waste, like volatile solids content (VS), organic carbon content (OC), cellulose (CEL), lignin (LIG), leaching tests, etc. However, other analyses, aimed at directly determining their degradative stability (biochemical methane potential (BMP), or respirometry tests, for instance), are still under research. This latter group of tests usually involves the necessity of specific equipment, higher experimental costs, and longer periods of time than conventional analyses to obtain the final results. On the other hand, since the equipment and experimental procedures have not been completely standardized yet, the reliability and comparability among results from different campaigns are difficult. Consequently, there is a great interest in finding a correspondence among the results of less laborious "conventional" analyses (like the mentioned VS content and other components like CEL, HEM...) and the more specific ones.

In this paper old waste characterization results published by several authors have been reviewed with the objective of bringing together the existing experience to obtain conclusions that could be generalized to other cases.

Firstly, used sampling and analysis techniques are briefly described, illustrating the different methodologies employed. Then, a comparative study of the relations between different parameters characterizing the organic content of waste (VS, CEL, HEM, LIG and their ratios) and BMP is presented. As a result, general correlation ranges between the studied parameters and guidance on their correspondence to the remaining biodegradability in old waste is given.

\section{Characterizing the stability of old landfills}

\subsection{Sampling}

The principal step in characterizing old waste consists in recovering historical data of the landfill using operator and fill records. Areas with different physical characteristics or history are determined at this stage to define the corresponding representative sampling points later. One to four samples per hectare have been recommended [1] but the sampling intensity depends on the heterogeneity of the site. A drill rig equipped with a bucket auger can be used to obtain samples from different depths $[2,3]$. The main problems of some drilling techniques are their high costs together with a significant sample alteration (fragmentation of landfilled materials), but they permit to observe the variation of waste properties with depth. Digging is cheaper and can be used to extract samples from landfills too, but it does not allow one to take deep samples. 
Once waste is collected, it must be thoroughly mixed and homogenized to prepare a representative composite sample. Then it can be transported to laboratory into plastic bags. Samples must be conserved and prepared before analyses. Different waste conservation procedures have been used: from fresh frozen [4] to alkali addition (to immobilise volatile acids) [5], but the most generalized method is oven drying at different temperatures (between 45 and $\left.105^{\circ} \mathrm{C}\right)$.

A classification of the main components and sizes usually constitutes the first analysis stage. Lobo et al [3] divided each fresh sample into three fractions: fines $(<20 \mathrm{~mm})$, middle $(20 \mathrm{~mm}<\varnothing<100 \mathrm{~mm})$ and coarse fraction $(>100 \mathrm{~mm})$. Then the middle and coarse fractions were manually divided into degraded components (unidentifiable materials), plastics, inert materials, metals, papercardboard, glass, textile, wood and special wastes. For the different assays a ground sample was prepared from each of the samples by mixing the degraded material, paper-cardboard, textile and wood fractions in the same proportion as they appeared in the original sample. However, some authors do not prepare a composite sample after classification, but only remove some components (stones, metals and plastics) that may damage the crushing equipment. Dried or moist samples can be grounded. Different particle sizes are recommended for each analysis: a size between $4 \mathrm{~mm}$ and $15 \mathrm{~mm}$ is fine enough for the majority of them.

\subsection{Waste analyses}

Many characterization results of fresh waste, individual components and mechanically-biologically treated waste have been published, as well as correlations between them [6]. However, few publications characterizing samples extracted from old landfills can be found. Most of these latter come from the attempt of assessing the stabilization state of bioreactor landfills [7-11]. Others directly tried to characterize old landfills $[12,13]$, study stabilization indicators and anaerobic biodegradability of the buried waste [14, 15] or establish correlations between different waste parameters $[2,16,17]$.

Table 1 shows the analyses used for old waste characterization in the consulted studies together with their fundamentals. Since there is not a standardized methodology, each study includes a different set of analyses.

On the other hand, the methodology used for some of the analyses varied among researchers. To determine the VS content, for example, different periods of calcination have been used by several authors.

Among the tests included in Table 1, the BMP test is one of the closest approaches to landfill biological stability, since its results try to be an estimate of the maximum quantity of methane that can be produced under anaerobic degradation within the landfill. Unfortunately, the assay presents great complexity: it must be done by triplicate, sometimes nutrient and seed addition is required, inhibition problems can appear due to acidification ... Moreover it requires extensive time: periods greater than 100 days have been suggested. Even though most tests performed are based on a method described by [18] or by [4], different periods of time, temperatures, or particle sizes in the waste sample 
have been used by the different researchers; sometimes the generated methane has been measured whereas other times the measured variable is the volume of gas; and different methodologies (with different accuracies) have been taken by researchers to measure it, such as syringes $[1,11]$ or water displacement methods $[12,13]$ combined with Gas Chromatography analyses. BMP is a good example of the difficulties described above and hence the interest in relating its value with the results of other analysis.

Table 1: $\quad$ Analyses in waste characterization.

\begin{tabular}{|c|c|}
\hline Analyses & Fundamentals \\
\hline $\begin{array}{l}\text { Moisture } \\
\text { content }\end{array}$ & $\begin{array}{l}\text { Weight of the loss of water when heating waste at } 45^{\circ} \mathrm{C} \text { or at } \\
105^{\circ} \mathrm{C} \text { until constant weight. }\end{array}$ \\
\hline $\begin{array}{l}\text { Volatile } \\
\text { solids content }\end{array}$ & $\begin{array}{l}\text { Weight of the loss of volatile material when heating a dry } \\
\text { sample at } 550^{\circ} \mathrm{C}\end{array}$ \\
\hline $\begin{array}{l}\text { Organic } \\
\text { carbon } \\
\text { content }(\mathrm{OC})\end{array}$ & $\begin{array}{l}\text { Detection, by an infrared detector, of } \mathrm{CO}_{2} \text { produced when a } \\
\text { sample reacts with oxygen at } 900-1300^{\circ} \mathrm{C} \text { (total } \mathrm{C} \text { ) minus } \mathrm{CO}_{2} \\
\text { produced when acidifying the sample and heating it in a } \\
\text { stream of oxygen (inorganic C) [15]. }\end{array}$ \\
\hline $\begin{array}{l}\text { Cellulose, } \\
\text { hemicellulose } \\
\text { and lignin } \\
\text { (CEL, HEM, } \\
\text { LIG) }\end{array}$ & $\begin{array}{l}\text { Cellulose is hydrolysed into glucose monomers in two stages } \\
\text { using sulphuric acid. Hemicellulose is determined by } \\
\text { measurement, through HPLC, of galactose, manose, xylose } \\
\text { and garabinose after digestion. The glucose measured then } \\
\text { comes from broken cellulose. The volatile suspended solids } \\
\text { (combusted at } 550^{\circ} \mathrm{C} \text { ) remaining after hydrolysis are } \\
\text { considered lignin }[8-11,14] \text {. }\end{array}$ \\
\hline $\begin{array}{l}\text { Biochemical } \\
\text { methane } \\
\text { potential } \\
\text { (BMP), Gas } \\
\text { production } \\
\text { (GP) }\end{array}$ & $\begin{array}{l}\text { Determination of the quantity of methane (or gas) from } \\
\text { anaerobically decomposing organic matter in laboratory batch } \\
\text { tests. The sample is incubated with a seed of appropriate } \\
\text { bacteria under optimised conditions and methane (or gas) } \\
\text { generation is measured by simultaneous measurements of gas } \\
\text { volume and composition }[2,4,6,7,14,17,18] \text {. }\end{array}$ \\
\hline $\begin{array}{l}\text { Respirometry } \\
(\mathrm{RA}, \mathrm{RI})\end{array}$ & $\begin{array}{l}\text { Assessment of the activity of a sample through its oxygen } \\
\text { consumption. The sample is mixed with a seed and incubated } \\
\text { under aerobic conditions. } \mathrm{CO}_{2} \text { production (converted to } \\
\text { oxygen consumption) or directly } \mathrm{O}_{2} \text { consumption are } \\
\text { measured }[1,6]\end{array}$ \\
\hline $\begin{array}{l}\text { FT-IR } \\
\text { spectroscopy }\end{array}$ & $\begin{array}{l}\text { Every stage of decomposition of the organic matter is } \\
\text { characterized by specific metabolic products that can be } \\
\text { identified by their absorption bands in the infrared spectrum } \\
{[17]}\end{array}$ \\
\hline $\begin{array}{l}\text { Hydrolysis } \\
\text { tests }\end{array}$ & $\begin{array}{l}\text { Dissolved organic carbon (DOC) released by enzymatic } \\
\text { hydrolysis, or substances like humic and fulvic acids are } \\
\text { determined as indicators of sample biodegradability [16] }\end{array}$ \\
\hline Leaching test & $\begin{array}{l}\text { Measurement of the contaminants released from the solid } \\
\text { phase into the water phase under the influence of different } \\
\text { reactions }[13,15] \text {. }\end{array}$ \\
\hline
\end{tabular}




\section{Relationship between biochemical stability parameters}

\subsection{BMP versus VS}

VS content is one of the simplest and cheapest methods to characterize the organic content of solids. It is obvious that no general law to relate this parameter to BMP can be established, since VS content does not distinguish between biodegradable and non biodegradable organic matter. However, assuming that each degraded solid produces the same quantity of methane for each particular waste (with "similar" chemical nature in VS), a lineal relation between both parameters can be expected. Several authors [2, 10,13] have tried to quantify this relation. Table 2 shows the published correlations together with the laws obtained in the present work based on published data.

Even though, the data compiled in $[7,10]$ do not show a clear correspondence, great part of the studied data $[9,11,12,15]$ present significant correlation between BMP and VS.

Greater BMP values per VS percentage are obtained in a study where BMP assays went on longer time [12], showing the influence of the experimental used methodology on the results.

Table 2: $\quad$ Correlations between BMP-VS.

\begin{tabular}{|c|c|c|c|c|c|c|}
\hline Slope & $\begin{array}{c}\text { Intersection } \\
\text { with y axis }\end{array}$ & $\mathbf{R}^{2}$ & $\mathbf{N}$ & Ref. & Type of samples & $\begin{array}{c}\text { Test } \\
\text { Duration } \\
\text { (d) }\end{array}$ \\
\hline $1.64^{1}$ & $-25.6^{1}$ & $0.77^{1}$ & 24 & {$[8,9]$} & $\begin{array}{l}\text { Outer Loop. } \\
\text { Bioreactor cells, } \\
\text { and control cells. }\end{array}$ & 60 \\
\hline $4.49^{1}$ & $-166.07^{1}$ & $0.71^{1}$ & 8 & [12] & $\begin{array}{c}\text { Kujala and } \\
\text { Ammassuo } \\
\text { Landfills }\end{array}$ & $>60$ \\
\hline $2.66^{1}$ & $-68.73^{1}$ & $0.63^{1}$ & 5 & {$[15]$} & $\begin{array}{c}1 \text { fresh, and } \\
\text { samples from 3-30 } \\
\text { years }\end{array}$ & $30-60$ \\
\hline $1.57^{1}$ & $-38.99^{1}$ & $0.62^{1}$ & 33 & [11] & $\begin{array}{c}\text { Yolo County } \\
\text { landfill }\end{array}$ & 45 \\
\hline $1.58^{1}$ & $-0.88^{1}$ & $0.38^{1}$ & $\tilde{250}$ & {$[2,7]$} & $\begin{array}{l}\text { Old landfills }(0-11 \\
\text { year-old waste) } \\
\text { 45-day tests }\end{array}$ & 45 \\
\hline $1.09^{2}$ & $+33.26^{2}$ & $0.17^{2}$ & 59 & [10] & Column study & 45 \\
\hline \multicolumn{2}{|c|}{ Global formula } & \multicolumn{5}{|c|}{$\begin{array}{l}\text { BMP }\left(\mathbf{L C H}_{\mathbf{4}} / \mathbf{k g ~ D M}\right)=\mathbf{1 . 8 5} * \mathbf{V S}(\%)-\mathbf{2 1 . 7 1} \\
\left(\mathrm{R}^{2}=0.48 ; \mathrm{n}=379\right) \\
\mathbf{B M P}(\mathbf{L C H} / \mathbf{k g D M})=\mathbf{2 . 0 1} * \mathrm{VS}(\%)-\mathbf{4 8 . 3 7} \\
\left(\mathrm{R}^{2}=0.61 ; \mathrm{n}=70\right) \text { Without data from }[7,10]\end{array}$} \\
\hline
\end{tabular}

(') Obtained from the cited author's results.

$\left({ }^{2}\right)$ Proposed by the author. 
Considering only the data with greater $\mathrm{R}^{2}[8,9,12,15,11]$, between 1.6 and $4.5 \mathrm{LCH}_{4}$ per $10 \mathrm{~g} \mathrm{VS}$ are generated, starting from VS contents between 16 and $37 \%$. Taking all the samples analysed in these studies, a rough estimate value of $2 \mathrm{LCH}_{4}$ per $10 \mathrm{gVS}$, from starting values of $24 \% \mathrm{VS}$ is obtained.

In any case, the BMP/VS relation depends on the biodegradability of the organic fraction of waste. When comparing results with the same experimental methods, higher slopes entail higher degradability of the organic fraction and thus higher contaminant potential remaining in that fraction. This ratio will change depending on the compounds that form the organic matter; it is specific for each kind of waste. Trying to find more general relations, correspondences between BMP and specific compounds are searched. Some results in this regard are discussed in the following sections.

\subsection{BMP versus cellulose and hemicellulose}

The organic fraction of typical fresh MSW is made up of 30-50\% of cellulosic substances that can undergo biological degradation. Cellulose and hemicellulose are the most significant carbon source for methanogenesis in landfills as their degradation contributes to around $90 \%$ of the total methane produced [16]. For this reason a close relation between BMP test results and cellulose and hemicellulose contents is expected. Nonetheless, some authors who have studied this ratio in sample series have not found important correlation coefficients. On the other hand, looking at other author's published series, $\mathrm{R}^{2}$ are obtained higher than in the case of BMP/VS (Table 3). Moreover, the obtained relations are quite similar in the different cases (between 2.52 and $2.76 \mathrm{~L} \mathrm{CH}_{4}$ per $10 \mathrm{~g}$ of CEL in waste, starting from CEL contents between 1.8 and $6.3 \%$ ).

Gathering different data series $[8,11,14]$ a general formula with $2.4 \mathrm{~L} \mathrm{CH}_{4}$ per $10 \mathrm{~g}$ of CEL, produced from CEL contents higher than $4 \%$ is obtained.

According to the stoichiometry of the theoretical reaction, a value of 4.14 $\mathrm{LCH}_{4}$ per $10 \mathrm{~g}$ of CEL should be obtained for $100 \%$ efficiency: different factors, such as the accessibility of CEL to the microorganisms, the gas volume detection limit, or even the CEL determination assay affect the experimental results.

Some authors link BMP with CEL + HEM content [14]. Obtained $\mathrm{R}^{2}$ in this case are significant too (and similar among different cases), but lower than in the previous case. The obtained slope is also smaller (between 1.96 and $2.21 \mathrm{LCH}_{4}$ per $10 \mathrm{~g} \mathrm{CEL}+$ HEM content), and it showed lesser methane generation from HEM during BMP (a theoretical generation of $3.73 \mathrm{LCH}_{4}$ per $10 \mathrm{~g}$ of HEM would be produced).

It is remarkable that the obtained formula for BMP-(CEL+HEM) results similar to that obtained for BMP-VS, with slopes of 1.82 and 1.85 and intercept values of -19.83 and -11.39 respectively, indicating that a little portion of VS was non biodegradable in these cases.

\subsection{BMP versus (Cellulose + Hemicellulose)/Lignin ratio}

The other parameter considered is Cellulose/Lignin ratio. It has been used by different authors $[2,13,10]$ as a measure of the relative "decomposition age" of 
the refuse. Cellulose is decomposable under anaerobic conditions whereas lignin degradability is little; so CEL/LIG or $(\mathrm{CEL}+\mathrm{HEM}) / \mathrm{LIG}$ ratios are direct indicators of the biodegradability of the organic fraction, regardless the organic content of the refuse. The values of a fresh refuse will be higher (values up to 4.15 have been reported [11]) than after its biodegradation (ratios as low as $<0.02$ were found in waste landfilled 10-20 years ago [14]).

Table 3: Correlations and formulae between BMP-CEL and BMPCEL+HEM.

\begin{tabular}{|c|c|c|c|c|}
\hline Slope & Intersection with y axis & $\mathbf{R}^{2}$ & $\mathbf{N}$ & Reference \\
\hline \multicolumn{5}{|c|}{ BMP-CEL } \\
\hline $2.61^{1}$ & $-8.64^{1}$ & $0.89^{1}$ & 16 & [8] \\
\hline $2.52^{1}$ & $-4.54^{1}$ & $0.76^{1}$ & 11 & {$[14]^{*}$} \\
\hline \multirow[t]{2}{*}{$2.76^{1}$} & $-17.436^{1}$ & $0.71^{1}$ & 33 & [11] \\
\hline & & $0.32^{2}$ & & [2] \\
\hline $2.17^{1}$ & $32.44^{1}$ & $0.30^{1}$ & 262 & [7] \\
\hline $1.11^{1}$ & $74.9^{1}$ & $0.05^{2}$ & 59 & [10] \\
\hline $\begin{array}{c}\text { Global } \\
\text { formula }\end{array}$ & \multicolumn{4}{|c|}{$\begin{array}{l}\text { BMP }\left(\mathrm{L} \mathrm{CH}_{4} / \mathbf{k g ~ D M}\right)=\mathbf{2 . 5 9} * \mathbf{C E L}(\%)+\mathbf{1 7 . 5 7}\left(\mathrm{R}^{2}=0.38 ; \mathrm{N}=381\right) \\
\text { BMP }(\mathbf{L ~ C H} / \mathbf{k g ~ D M})=\mathbf{2 . 5 7} * \mathbf{C E L}(\%)-10.92\left(\mathrm{R}^{2}=0.83 ; \mathrm{N}=60\right) \text { Without } \\
\text { data from }[7,10]\end{array}$} \\
\hline \multicolumn{5}{|c|}{ BMP-(CEL+HEM) } \\
\hline $2.14^{1}$ & $-10.28^{1}$ & $0.87^{1}$ & 16 & [8] \\
\hline $2.21^{1}$ & $-19.662^{1}$ & $0.69^{1}$ & 33 & [11] \\
\hline $1.96^{2}$ & $-4.97^{2}$ & $0.68^{2}$ & 11 & {$[14]^{*}$} \\
\hline $\begin{array}{c}\text { Global } \\
\text { formula }\end{array}$ & \multicolumn{4}{|c|}{$\begin{array}{l}\text { BMP }(\mathbf{L ~ C H} / \mathbf{k g ~ D M})=1.85 *(C E L+H E M)-11.39 \\
\left(\mathrm{R}^{2}=0.68 ; \mathrm{N}=60\right) .\end{array}$} \\
\hline
\end{tabular}

${ }^{1}$ Obtained from the cited author's results; ${ }^{2}$ Proposed by the author; * 43 days of assay.

Table 4: $\quad$ Correlations and formulae between BMP-(CEL+HEM)/LIG.

\begin{tabular}{|c|c|c|c|c|}
\hline Slope & Intersection with y axis & $\mathbf{R}^{\mathbf{2}}$ & $\mathbf{N}$ & Reference \\
\hline $36.16^{1}$ & $-9.48^{1}$ & $0.87^{1}$ & 24 & {$[9]$} \\
\hline $135.35^{2}$ & $-4.32^{2}$ & $0.67^{2}$ & 11 & {$[14]$} \\
\hline $49.56^{1}$ & $-33.09^{1}$ & $0.62^{1}$ & 33 & {$[11]$} \\
\hline
\end{tabular}

Obtained from the cited author's results. ${ }^{2}$ Proposed by the author.

Nevertheless, these ratios are not useful to compare biodegradability of different waste, since they do not consider their inorganic fraction. Because of this, the theoretical relation BMP - CEL/LIG is not linear, though both parameters show the same trend, decreasing with the degradation. Anyway, in [14] a linear relation between both parameters is proposed with similar correlations to those obtained in this study. Considering other data $[9,11]$, comparable $\mathrm{R}^{2}$ are obtained although the obtained laws are different (Table 4 ). In 
this case higher (CEL+HEM)/LIG ratios imply higher content of biodegradable organic solids.

\subsection{Other parameters}

The results of other tests such as total organic carbon (TOC) in the solid, dissolved organic carbon (DOC) after leaching assays, respirometry, gas production (GP) or enzymatic assays have been related to BMP.

A high linear correlation $\left(\mathrm{R}^{2}=0.97\right)$ between $\mathrm{DOC}$ and BMP is inferred from the published data [15]. On the other hand, [16] found good correspondence of enzymatic assays with BMP ( $\mathrm{R}^{2}$ from 0.65 to 0.87 from three different Belgian landfills).

Even though there are many papers that compare respirometry with BMP or GP in mechanically biologically treated (MBT) and fresh waste, little research has been published regarding old excavated samples. Cossu and Raga [19] found high correlation coefficients $\left(\mathrm{R}^{2}=0.80\right)$ between gas generated throughout 21 days $\left(\mathrm{GS}_{21}\right)$ and the respirometry index corresponding to 4 days $\left(\mathrm{AT}_{4}\right)(\mathrm{n}=21$ samples extracted from three different landfills).

On the other hand several techniques are nowadays in development to obtain estimates for $\mathrm{AT}_{4}$ and $\mathrm{GS}_{21}$ in MBT waste, like FT-IR together with statistical tools [17]. These assays should be standardized and the relations between different parameters should be deeply studied. Then, they could also be of interest to assess landfill's stability.

\section{Conclusions}

Different kinds of assays have been proposed by a number of authors to characterize waste degradability in old landfills. In this paper, the techniques used for sample extraction and conservation are summarized together with those used for laboratory analyses. Since there is not standardized methodology yet, some assays are performed in a different way by each author. BMP, the test that most directly characterizes waste biodegradation stability in landfills, is precisely one of the tests that more variability presents in different laboratories. For this reason among others, several authors try to relate the obtained BMP results to other assays. Since the results published by diverse authors have been obtained by using different methodologies, no generalizable conclusions can be drawn from the available information in this regard. However, analysing the published data, an approach to BMP based on its relation to the VS content, CEL, HEM and their rate to the LIG content of waste have been proposed in this paper.

For a specific material, VS, CEL, CEL+HEM and (CEL+HEM)/LIG can be employed as indicators of the degradation state, since they all diminish when the degradation state is higher. However, only CEL and CEL+HEM contents permit to compare the biodegradability of different materials. Accepting the same accessibility conditions to the compounds, the same linear relation between these parameters and BMP should be applicable to different kinds of waste. On the other hand, even though VS content does not give information about the degradability of the studied matter, it decreases together with the biodegradable 
fraction throughout the degradation process. That is why, for a particular waste, accepting that each VS produces the same $\mathrm{CH}_{4}$ quantity, a linear relation to BMP results is expected as well. In turn, $(\mathrm{CEL}+\mathrm{HEM}) / \mathrm{LIG}$ ratio does not include information about the whole quantity of biodegradable substances. Its relation to BMP is not linear, since it depends on the fraction of non biodegradable organic content in each sample (which is higher when the sample is more degraded).

The analyzed results, published by different authors, show a generalized correspondence between the mentioned parameters (except for [2] and [10]). The $\mathrm{BMP} /$ parameter ratios obtained for the different studies are similar in the case of CEL and HEM+CEL contents, as expected. On the contrary, studying VS content and (CEL+HEM)/LIG ratio, the relation to BMP changes in the different cases, which correspond to dissimilar waste.

These results confirm that absolute BMP values can be estimated from CEL and HEM contents, taking into account that these compounds cannot be completely decomposed under landfill conditions. On the other hand, for the same kind of waste (whatever its age is), laws between VS and $(\mathrm{HEM}+\mathrm{CEL}) / \mathrm{LIG}$ and BMP can be established. However, to obtain more accurate values and be able to compare different wastes and studies a standardization of the assays is indispensable.

On the other hand, more research is needed when trying to relate BMP of old waste to other analyses, such as respirometries, that have shown high $\mathrm{R}^{2}$ values when applied to MBT waste or other promising techniques, such as FT-IR [17].

\section{References}

[1] Heyer, K.-U. Long term emissions from landfills. Proc. of the Superior Course On Sustainable Landfilling, CalRecovery, Inc. and Instituto para la Sostenibilidad de los Recursos: Madrid, 2006.

[2] Kelly, R. J., Shearer, B. D., Kim, J., Goldsmith, C. D. Hater, G. R. \& Novak, J. T. Relationships between analytical methods utilized as tools in the evaluation of landfill waste stability. Waste Management, 26(12), pp. 1349-1356, 2006.

[3] Lobo A., Cobo N., López A. \& Cacho L. Advances in old landfill assessment. (Chapter 6) Landfill Research Trends, ed. Nova Science Publishers, pp. 167-189, 2007.

[4] Owens, J. M. and Chynoweth, D. P. Biochemical methane potential of municipal solid waste (MSW) components. Wat. Sci. Tech. 1993, 27, 1-14.

[5] Harries C., Cross C. \& Smith R. Development of a biochemical methane potential (BMP) test and application to testing of municipal solid waste samples. Proc. of the $8^{\text {th }}$ Int. Waste Management and Landfill Symposium, eds. CISA, Environmental Sanitary Engineering Centre: Italy, 2001.

[6] Environment Agency. (2005). Guidance on monitoring MBT and other pretreatment processes for the landfill allowances schemes (England and Wales). Www.environment-agency.gov.uk/commondata/ acrobat/ mbt_1154981.pdf 
[7] Kelly, R.J. Solid Waste Biodegradation Enhancements and the Evaluation of Analytical Methods Used to Predict Waste Stability. Thesis for Master of Science in the Faculty of Virginia Polytechnic Institute and State University. http://scholar.lib.vt.edu/theses/available/etd-05102002-131001/ unrestricted/etd.pdf

[8] Hater, G. R., Eith, A. E., Goldsmith, C. D., Green, R. B. \& Barbush, J. A. Bioreactor study at the waste management Outer Loop Landfill. Proc. of Geo-Frontiers, Texas, 2005.

[9] Landfill bioreactor performance. Second interim report Outer Loop Recycling \& Disposal Facility, Louisville Kentucky. U. S. Environmental Protection Agency, Online. www.epa.gov/nrmrl/pubs/600r07060/ 600R07060.pdf

[10] Shearer B. Enhanced Biodegradation in Landfills. Thesis for Master of Science in Environmental Engineering. Faculty of Virginia Polytechnic Institute and State University. http://scholar.lib.vt.edu/theses/available/etd05252001-155108/unrestricted/1thesis.pdf

[11] Mehta, R.; Barlaz, M. A.; Yazdani, R.; Augenstein, D.; Bryars, M. \& Sinderson, L. Refuse decomposition in the presence and absence of leachate recirculation. Journal of Environmental Engineering, 128(3), pp. 228-236, 2002.

[12] Sormunen K., Ettala M. \& Rintala J. Detailed internal characterisation of two Finnish landfills by waste sampling. Waste Management, 28(1), pp. 151-163, 2008.

[13] Ham, R. K., Norman, M. R. and Fritschel, P. R. Chemical characterization of Fresh Kills Landfill refuse and extracts. Journal of Environmental Engineering, 119(6), pp. 1176-1195, 1993.

[14] Wang Y., Byrd C.S. \& Barlaz M. Anaerobic biodegradability of cellulose and hemicellulose in excavated refuse samples using a biochemical methane potential assay. Journal of Industrial Microbiology, 13, pp. 147153, 1994.

[15] Francois V., Feuillade G., Skhiri N., Lagier T. \& Matejka G. Indicating the parameters of the state of degradation of municipal solid waste. Journal of Hazardous Materials, B137, pp. 1008-1015, 2006.

[16] Rodriguez C., Hiligsmann S., Ongena M., Charlier R. \& Thonart P. Development of an enzymatic assay for the determination of cellulose bioavailability in municipal solid waste. Biodegradation, 16, pp. 415-422, 2005

[17] Binner E., Meissl K. \& Tesar M. Assessment of MBT-Waste- A new approach to avoid failures by respiration activity. Proc. of the $11^{\text {th }}$ Int. Waste Management and Landfill Symposium, eds. CISA, Environmental Sanitary Engineering Centre: Italy, 2007.

[18] Shelton, D.R. \& Tiedje J.M., General method for determining anaerobic biodegradation potential. Applied and Environmental Microbiology, 47(4), pp. 850-857, 1984.

[19] Cossu, R. \& Raga R. Test methods for assessing the biological stability of biodegradable waste. Waste Management, 28(2), pp. 381-388, 2008. 